\title{
Small-Volume Resuscitation from Hemorrhagic Shock by Hypertonic Saline Dextran - Conceptional Basis and Historical Background
}

\author{
Uwe Kreimeier ${ }^{a, b}$ Stephan Prueckner ${ }^{a, b}$ \\ a Department of Anesthesiology and ${ }^{b}$ Institute for Surgical Research, Ludwig-Maximilians-University Munich, \\ Grosshadern, Munich, Germany
}

\section{Key Words}

Hemorrhagic shock • Volume therapy · Hypertonic saline - Dextran - Regional blood flow · Microcirculation • Endothelium

\section{Introduction}

Early and adequate fluid resuscitation is essential for the survival of the severely hypovolemic trauma patient. Studies have shown that, besides age, severity of injury and arterial hypotension, the duration of shock is the most important factor influencing the recovery from multiple trauma [1]. While for optimal resuscitation rapid restoration of blood volume is essential, the lack of compatible blood or blood components for infusion at the accident site has directed therapy towards the use of blood substitutes. The controversy regarding the relative merits of crystalloids and colloids for primary volume therapy has been exacerbated by conflicting results and, recently, by cost considerations. The increasing involvement of paramedics in the primary care of accident and emergency cases has highlighted the requirements for the 'ideal' solution for primary resuscitation. These are efficacy, practicability and safety.
Early reports showed that, on average, only 500 to $1,000 \mathrm{ml}$ of any fluid is given prior to hospital arrival [2]. Due to the short transportation intervals in many sites these data have not substantially changed. The crucial factor thus remains early and adequate resuscitation of the patient from shock with its characteristic sequelae of severely compromised microcirculation. This requirement has focused the interest in hypertonic saline/colloid solutions which, when given as small-volume bolus infusions, have a pronounced effect on the cardiovascular system. The data from both experimental and clinical studies suggest that these solutions should be particularly useful for primary resuscitation in severe trauma.

\section{Early Studies on Hypertonic Electrolyte Solutions}

The first report of the beneficial effects of administering isotonic saline solutions to patients suffering from hemorrhagic shock was made by Penfield [3]. Later Silbert [4] showed that this treatment was also effective in patients suffering from Buerger's disease. The first investigation of the clinical efficacy of small-volume bolus infusions of hypertonic saline solutions was made by De Felippe et al. [5], who reported on the effect of repetitive intravenous injections of $50-\mathrm{ml}$ aliquots of $7.5 \%$ sodium

Priv.-Doz. Dr. med. U. Kreimeier

Department of Anesthesiology, Ludwig-Maximilians-University Munich, Grosshadern Marchioninistrasse 15, D-81377 München (Germany)

Tel. +49 897095 6412, Fax +49 8974502817

E-Mail kreimeier@ana.med.uni-muenchen.de 
chloride into 12 patients suffering from hypovolemic shock which had been refractory to vigorous volume replacement and corticosteroid therapy as well as to catecholamines. They noted that infusions of 100-400 $\mathrm{ml}$ of the hypertonic sodium chloride solution resulted in an immediate rise of arterial pressure, resumption of urine flow and recovery of consciousness. The beneficial effects of these infusions tended to persist for several hours, during which it was noted that the volume of isotonic fluids required to sustain the new state was reduced by $90 \%$ compared to patients resuscitated with conventional isotonic fluids. After this prompt reversal of shock 9 of the 12 patients were ultimately discharged from hospital.

De Felippe's report [5] on the clinical application of small-volume infusion followed on a series of studies performed on animals which had been submitted to hemorrhagic shock. In one such study, Brooks et al. [6] investigated the efficacy of $2.74 \%$ sodium bicarbonate and $1.8 \%$ $\mathrm{NaCl}$ solutions in preventing tissue damage in mongrel dogs which had been subjected to $90 \mathrm{~min}$ hemorrhagic hypotension (mean arterial pressure, MAP $=40 \mathrm{~mm} \mathrm{Hg}$ ). When resuscitated with either of the two solutions, the dogs made rapid recoveries; furthermore the workers found no evidence of tissue lesions. Reinert [7] used hypertonic solutions to resuscitate rats from 'irreversible' hemorrhagic shock (MAP $=30 \mathrm{~mm} \mathrm{Hg}$ for $180 \mathrm{~min}$ ). He found that on reinfusing $30-40 \%$ of the shed blood volume together with either $6-7 \mathrm{ml}$ of $1.8 \%$ or $1.25-1.5 \mathrm{ml}$ of $10 \% \mathrm{NaCl}$ (i.e. equivalent amounts of solute delivery in each case), the survival rates were $5 / 6$ and $2 / 5$ animals, respectively. The authors concluded that, besides solute, sufficient fluid had to be provided.

Baue et al. [8] were the first to use hypertonic solutions combined with a colloid for the initial stage of post-hemorrhagic resuscitation. In experiments on beagles they used $\mathrm{NaHCO}_{3}, \mathrm{NaCl}$ and dextrose as crystalloid solutes and dextran as colloid. They demonstrated that the increase in cardiac output and mesenteric flow, measured using electromagnetic flow probes, which occurred after primary resuscitation was related to the concentration of the solute administered. They also noted that the hematocrit fell after infusion of the hypertonic solutions, and that the extent of the hemodilution was related to the amount of solute delivered. On the basis of these observations the authors suggested that both intravascular volume and blood flow were increased through the mobilization of body water ('autotransfusion').

The use of small volume of highly concentrated sodium chloride $(2,400 \mathrm{mosmol} / \mathrm{kg})$ was investigated by Velasco et al. [9]. They used dogs subjected to hemorrhagic hypotension (MAP $=40 \mathrm{~mm} \mathrm{Hg}$ for $30 \mathrm{~min}$ ). They found that the infusion of $4 \mathrm{ml} / \mathrm{kg}$ body weight of $7.5 \% \mathrm{NaCl}$, given without any further volume substitution, rapidly restored both MAP and acid-base equilibrium and resulted in indefinite survival of all animals, whereas all ten control animals receiving identical amounts of isotonic saline died. Rocha e Silva et al. [10] studied the survival rates as well as hemodynamic and metabolic effects of resuscitation with hypertonic solutions containing either sodium salts, chloride and/or non-electrolytes. They found that plasma sodium but not plasma osmolality was significantly correlated with survival, and concluded that high plasma sodium was essential for survival. These data, however, were at variance with the earlier observations of Messmer [11], who had demonstrated that the beneficial effect of hypertonic solutions (1,200 mosmol/ $\mathrm{kg}$ ) in rats subjected to hemorrhagic shock (MAP = $30 \mathrm{~mm} \mathrm{Hg}$ for $240 \mathrm{~min}$ ) depended upon the tonicity but not upon the concentration of sodium ions in the solution per se.

McNamara [12] found that intravenous injections of $50 \%$ glucose solution ( $1 \mathrm{ml} / \mathrm{kg}$ body weight) during hypovolemic shock in rabbits raised MAP significantly and improved long-term survival compared to the survival achieved by similar osmolar loads of either normal saline or $25 \%$ mannitol solution. In the light of the widespread use of Ringer's lactate solution for resuscitation, Cone et al. [13] investigated the efficacy of resuscitating with a hypertonic lactate saline solution (sodium $250 \mathrm{mM}$, chloride $100 \mathrm{~m} M$, lactate $150 \mathrm{~m} M$ ) using conscious dogs which had been subjected to acute, major blood loss. They found that animals treated with hypertonic lactate/saline solution required smaller volumes of fluid to normalize and then maintain cardiac output and MAP, and that these animals sustained a better urine output. It was also noted that, despite rapid infusion, neither significant nor protracted plasma hyperosmolality was observed.

Traverso et al. [14] compared the effects of administration of various concentrations of sodium chloride solutions $(0.9,5,7.5$, and $10 \%)$ in unanesthetized pigs which had been subjected to severe hemorrhage. The fluid volume substituted was 14 and $25 \%$ of the shed blood, which was equivalent to 8 and $14 \mathrm{ml} / \mathrm{kg}$ body weight, respectively. They found that $7.5 \% \mathrm{NaCl}$ solution given at $14 \mathrm{ml} / \mathrm{kg}$ body weight produced significantly better survial rates compared to the other concentrations studied. By contrast, the use of $10 \% \mathrm{NaCl}$ was associated with early death, which might have been due to the negative inotropic effect of rapid infusion of extremely hypertonic solutions. 


\section{Role of Hypertonic Dextran Solutions}

The duration of the cardiovascular response to the infusion of hypertonic dextran solutions was investigated by Smith et al. [15]. They studied the responses to six solutions $\left(\mathrm{NaCl}, \mathrm{NaCl} / \mathrm{NaHCO}_{3}, \mathrm{NaCl} /\right.$ sodium acetate, $\mathrm{NaCl} /$ mannitol, $\mathrm{NaCl} / 6 \%$ dextran 70 , glucose) each with a tonicity of $2,400 \mathrm{mosmol} / \mathrm{kg}$ in conscious sheep. Their results suggested that animals subjected to standardized hemorrhagic shock were best resuscitated when they received a single bolus infusion of $7.5 \% \mathrm{NaCl} / 6 \%$ dextran 70. In these animals, the cardiac output remained at significantly higher levels during the 3-hour observation period. These observations were confirmed by Kramer et al. [16], who demonstrated that following small-volume resuscitation of severely hemorrhaged conscious sheep by infusion of $200 \mathrm{ml}$ of hypertonic saline/dextran $(2,400$ mosmol $/ \mathrm{kg}, 6 \%$ dextran 70 , which is slightly hyperoncotic), both cardiovascular and metabolic functions were fully restored for at least $30 \mathrm{~min}$ post-resuscitation. Furthermore, the total volume requirements were significantly lower than those needed when using normal saline for primary resuscitation.

Maningas et al. [17] also noted the efficiency of the hypertonic saline/dextran 70 mixture. In a study on conscious pigs they observed that after the removal of $46 \mathrm{ml}$ of blood per $\mathrm{kg}$ body weight over a period of $15 \mathrm{~min}$, replacement of $25 \%$ of the shed volume by $7.5 \% \mathrm{NaCl} / 6 \%$ dextran 70 resulted in a 100\% survival rate (over a 96hour observation period).

The efficacy of administering colloids for prolongation of the circulatory effects which had been initiated by hypertonic saline is not restricted to the use of dextran 60 or 70. Hetastarch has been shown to be effective both in experimental hypovolemic and endotoxin shock $[18,19]$. Results from one of these studies in which the effects of using $7.5 \%$ saline $/ 6 \%$ dextran were compared to those obtained resuscitating with $7.5 \%$ saline $/ 6 \%$ hetastarch showed that both colloids maintained cardiovascular function for a longer period than hypertonic saline alone [18]. It was also observed that the hypertonic saline/dextran solution gave a slightly better response than the solution containing hetastarch. The difference was attributed to the possibility that dextran gave a higher effective oncotic pressure and was cleared more slowly from the intravascular space.

In studies using a canine model, developed to parallel the normal hemorrhagic resuscitation regimen, Kreimeier and Messmer [20] studied the effects of hypertonic (7.2\%) saline, hyperoncotic $(10 \%)$ dextran 60 , and the combina- tion of the two solutes on lung function, central hemodynamics and nutritional blood flow. Even though only small volumes of the selected fluid ( $4 \mathrm{ml} / \mathrm{kg}$ body weight), which was equivalent to $10 \%$ of the shed blood, were injected intravenously, within $5 \mathrm{~min}$ restoration of macro- and microhemodynamics were observed. The addition of $10 \%$ dextran 60 to the $7.2 \%$ saline solution resulted in higher cardiac output and oxygen delivery to the tissues as compared to hypertonic saline alone.

In 1988, in this journal Kreimeier et al. [21] reported on most favorable results obtained from a detailed analysis of the effects of hypertonic saline as well as hypertonic saline/hyperoncotic dextran 60 solution on regional blood flow when given as primary resuscitation from hemorrhage. Regional blood flow was determined in 11 organs by means of radioactively labeled microspheres $15 \mu \mathrm{m}$ in diameter. 18 beagles under anesthesia and controlled ventilation were bled to a MAP of $40 \mathrm{~mm} \mathrm{Hg}$, which was maintained for $45 \mathrm{~min}$. Then $10 \%$ of the shed blood volume were substituted intravenously within $2 \mathrm{~min}$ by either $7.2 \%$ saline alone, $10 \%$ dextran 60 alone, or a combined hypertonic-hyperoncotic solution containing $7.2 \%$ saline $/ 10 \%$ dextran 60 . The data revealed that already $5 \mathrm{~min}$ after the infusion of $4 \mathrm{ml} / \mathrm{kg}$ body weight of both hypertonic solutions, cardiac output had increased beyond the initial control values, while peripheral vascular resistance was significantly decreased. Stroke volume index was highest upon hypertonic-hyperoncotic saline/ dextran resuscitation. MAP reached $70 \mathrm{~mm} \mathrm{Hg}$, corresponding to $60 \%$ of control and did recover during further volume substitution. At the end of the hypotension period, the regional blood flow had significantly decreased in all organs except brain, heart and adrenal glands. $5 \mathrm{~min}$ after bolus injection of either of the three test solutions, however, blood flow to the brain, adrenal glands and colon had increased above baseline, while control values were regained in kidneys, small intestine, liver and thyroid gland. Moreover, myocardial blood flow was 2-3 times the baseline values and had increased in all regions of the heart investigated. Blood flow to the pancreas and gastric mucosa remained diminished (fig. 1). The total peripheral arteriovenous shunt calculated for $15-\mu \mathrm{m}$ diameter microspheres decreased during hypotension and remained low upon primary volume substitution by means of either of the three solutions under investigation (14-20\% of cardiac output), indicating resumption of nutritional blood flow in general. For the first time, these results thus impressively documented the instantaneous restoration of both the macro- and microhemodynamics with normalization of nutritional blood flow within $5 \mathrm{~min}$ 
after primary resuscitation by means of hypertonic saline/ hyperoncotic dextran solution [21].

\section{Specific Effect of Hypertonic Saline/Colloid Solution on Post-Ischemic Leukocyte/ Endothelial Interaction}

Chemotactic accumulation of circulating leukocytes and their adhesion to the endothelial lining of postcapillary venules have long been recognized as key features of post-ischemic reperfusion injury $[22,23]$. The molecular mechanisms of leukocyte adhesion to endothelial cells in response to hyperosmolarity have been investigated by Thiel et al. [24] in vitro. Incubation of isolated leukocytes in buffer solutions with increasing osmolarity seems to counteract the FMLP-induced upregulation of $\beta_{2}$-integrins in a dose-dependent manner. At the same time FMLP-induced shedding of $L$-selectin is reduced, suggesting that these changes are not due to a nonspecific artifact, such as effects of the hypertonic medium on epitope-antibody recognition [25]. When compared to physiologic osmolarity (290 mM), FMLP-induced CD18 upregulation and $L$-selectin shedding were significantly reduced at osmolarities that are typically found in humans and animals after resuscitation with hypertonic solutions.

Special pharmacologic properties exist and speak for the combined use of hypertonic saline together with a colloid: Nolte et al. [26] published their data on the leukocyte/endothelial interaction of hypertonic-hyperoncotic dextran solution after ischemia/reperfusion injury in the hamster dorsal skin fold model. The authors demonstrated that after $4 \mathrm{~h}$ of ischemia and reperfusion of striated muscle the number of leukocytes adhering to the endothelium of postcapillary venules was significantly reduced for $24 \mathrm{~h}$ after bolus infusion of $7.2 \% \mathrm{NaCl} / 10 \%$ dextran 60 and hypertonic saline/dextran effectively attenuated macromolecular leakage and reduced capillary endothelial swelling as assessed by measurements of capillary luminal diameters. The hypertonic saline alone was significantly less efficient in protecting from post-ischemic leukocyte/endothelial interaction and its sequelae.

The impact of the synthetic colloid dextran is also known from hemodilution experiments: Already very small amounts of dextran have been shown to be capable of reducing reperfusion injury after a period of shock and low/no flow in the microcirculation [27, 28]. In the same animal model, post-ischemic leukocyte accumulation and adherence were found to be significantly attenuated following prophylactic isovolemic hemodilution with $6 \%$

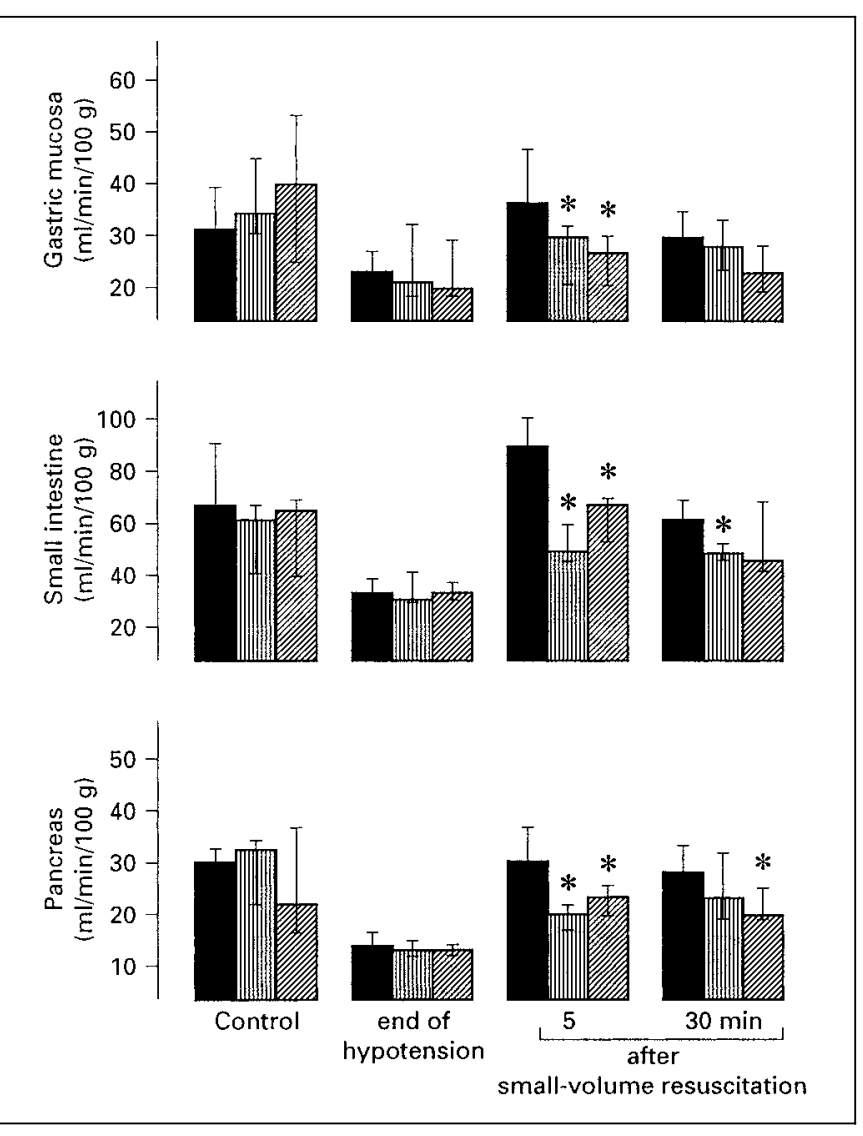

Fig. 1. Changes in regional blood flow in gastric mucosa, small intestine and pancreas during hemorrhagic hypotension and after smallvolume resuscitation by means of hypertonic saline/hyperoncotic dextran $60 . \square=7.2 \% \mathrm{NaCl} / 10 \%$ dextran 60 : HHS; 血=10\% dextran 60: HDS; $\mathbb{Z}=7.2 \% \mathrm{NaCl}$ : HSS. Median, q1-/q3-quartile, ${ }^{*} \mathrm{p}<0.05$ vs. $7.2 \% \mathrm{NaCl} / 10 \%$ dextran 60 .

dextran 60 to a hematocrit of $30 \%$ - a value clinically relevant in the trauma patient - when compared to controls [29]. This effect was absent when using $6 \%$ hydroxyethyl starch, and the authors postulated a compound-specific pharmacologic effect of dextran.

\section{Basic Mechanisms of Action}

Intravenous bolus application of hypertonic sodium chloride results in a rapid and pronounced increase of the plasma sodium concentration and thereby initiates a steep transmembranous osmotic gradient. The most important mechanism of action of hypertonic saline is the instantaneous mobilization of endogenous fluid along the osmotic gradient with increase of intravascular volume [30, 31] (fig. 2). In addition, direct myocardial stimula- 


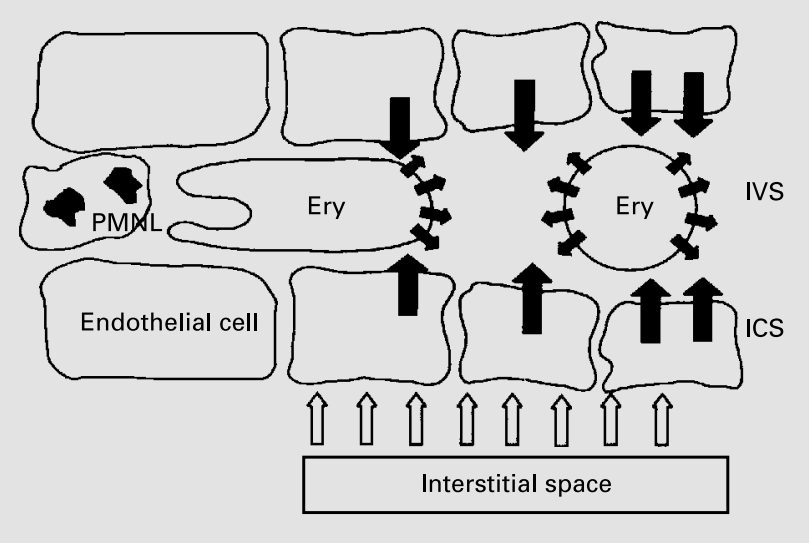

Fig. 2. Endogenous fluid shift induced by hyperosmolarity: The intravascular volume gain primarily stems from the endothelial cell lining in response to the rapid and pronounced increase of the plasma sodium concentration and thereby steep transmembranous osmotic gradient. IVS = Intravascular space, ICS = intracellular space, $\mathrm{PMNL}=$ polymorphonuclear leukocyte.

tion, CNS stimulation, neurogenic reflex mechanisms, enhanced sympathetic discharge, hormone release, improvement of blood fluidity, re-establishment of spontaneous arteriolar vasomotion, and peripheral arterial vasodilatation have been discussed as mechanisms of action $[30,32]$. Data from experimental studies in dogs with burn injury [33] and in pigs resuscitated from hemorrhagic shock [34] have failed, however, to confirm a direct myocardial stimulating effect. The authors were unable to demonstrate significant changes in the end-systolic pressure-volume relationship, and stroke work-end-diastolic volume relationship [33], or end-systolic elastance and segmental preload recruitable stroke work [34] upon hypertonic saline bolus infusion. Both groups of investigators attribute the circulatory effect to rapid augmentation of ventricular preload and a reduction of afterload.

Vassar and Holcroft [35], on the basis of their broad clinical experience in the field of small-volume resuscitation, estimate that administration of $250 \mathrm{ml} 7.5 \% \mathrm{NaCl} /$ $6 \%$ dextran 70 to a $70-\mathrm{kg}$ patient who has suffered a 2 -liter blood loss will result in plasma volume expansion of at least $700 \mathrm{ml}$. To achieve equivalent plasma volume expansion with lactated Ringer's solution, these authors estimate 2.8 liters of solution to be necessary. Mazzoni et al. [31] have calculated that, after a $20 \%$ blood loss, $7.5 \%$ saline solution given over $10 \mathrm{~s}$ in an amount equivalent to $1 / 7$ of the actual blood loss allows to re-establish normal blood volume within $1 \mathrm{~min}$. These authors ascribe the instantaneous circulatory effect to the rapid influx of fluid first of all from the microvascular endothelium and red blood cells $[31,36]$. This fluid shift effect is most pronounced in those capillary districts with swollen endothelium: the more swollen the endothelium, the greater is the effect of hypertonic solutions in reducing hydraulic resistance and improving tissue perfusion [31]. In another study, Mazzoni et al. [37] investigated the volume changes of endothelial cell monolayers on exposure to anisotonic media, from which can be deduced that the increase in plasma osmolality to $460 \mathrm{mosmol} / \mathrm{kg}$ - which is transiently obtained at the end of bolus infusion of $7.5 \%$ saline [31] - should result in shrinkage of endothelial volume by $20 \%$.

Further results from animal studies have suggested that the rapid cardiovascular response to hypertonic solutions with increase of cardiac output and restoration of peripheral blood flow might, at least in part, be mediated by the instantaneous release of eicosanoids [38] with an enhanced 6-keto- $\mathrm{PGF}_{1 \alpha} /$ thromboxane $\mathrm{B}_{2}$ ratio [39]. This may also explain the characteristic, acute hypotensive response observed following rapid hypertonic saline infusion in dogs, which is not mediated by cardiac depression, but by a decrease in total peripheral resistance [40]. Since, from studies of endothelial cells grown on beads, the link between capillary flow (shear-stress) and the production of nitric oxide has been emphasized [41], the involvement of NO in this process seems most likely.

The neuroendocrine response to resuscitation with $7.5 \% \mathrm{NaCl} / 6 \%$ dextran 70 following hemorrhagic hypotension has been quantified in conscious pigs [42]. Following small-volume resuscitation plasma $\mathrm{ACTH}$, cortisol and aldosterone levels decreased, this effect, however, being primarily due to hemodilution associated with the expansion of plasma volume. In contrast, the reduction in plasma norepinephrine, epinephrine, lysine, vasopressin and plasma renin concentration was greater than attributed to hemodilution alone, which indicates also a role of altered hormone release.

\section{Resumé and Clinical Impact}

The concept of small-volume resuscitation - the rapid infusion of a small dose $(4 \mathrm{ml} / \mathrm{kg}$ body weight $)$ of 7.2 $7.5 \% \mathrm{NaCl} /$ colloid solution - has been advocated for initial therapy of severe hypovolemia and shock almost two decades ago. It is based on the instantaneous mobilization of endogenous fluid along the osmotic gradient from intracellular into the intravascular compartment. For primary volume resuscitation from severe hypovolemia and 
shock this is attractive for reasons of rapid mobilization of endogenous water, especially from the intracellular compartment representing a huge reservoir amounting to about 251 of fluid. In addition, during shock and ischemia the endothelial cell volume in particular increases due to loss of ATP of the cells and cell membrane exchange dysfunction, leading to accumulation of water in the cells. Thus any mobilization of water from this intracellular site bears two important advantages: (1) plasma volume is rapidly increased to 3- to 4-fold the volume infused; (2) by normalization of the endothelial cell volume the luminal diameter of the microvessels increases, consequently the microcirculatory blood flow.

In the preclinical scenario this is attractive with regard to the small infusion volume needed to elicit an instantaneous cardiovascular effect without the risk of fluid overload. Moreover, this concept is unique with regard to the specific mode of action at the microvascular level providing prompt restoration of nutritional blood flow. During the 80 s various research groups were able to demonstrate in clinically relevant animal models of hemorrhagic as well as traumatic shock that even in the presence of a $50 \%$ blood loss a volume as small as $4 \mathrm{ml} / \mathrm{kg}$ of $7.2-7.5 \% \mathrm{NaCl}$ is sufficient to restore cardiac output and regional organ blood flow to pre-shock values almost instantaneously, while at the same time systemic arterial pressure is significantly increased. In prehospital trials, small-volume resuscitation by means of hypertonic saline/colloid solution have shown favorable results in hypotensive trauma patients [43], in case of severe trauma requiring immediate surgery [44], and in patients with head trauma with a Glasgow Coma Scale of 8 or less in the presence of hypotension (systolic blood pressure $<90 \mathrm{~mm} \mathrm{Hg}$ ) [45, 46].

\section{Epilogue}

Decades of studies have solved many of the problems concerning the pathogenesis of hemorrhagic shock. In 1985 Schoenberg, Smedegard, Gerdin, Messmer and Ar- fors presented the 'uptake-model' of hemorrhagic shock, i.e. terminating the duration of hypotension when an uptake volume of $15 \%$ of the animal's shed blood had been reached. They arrived at a reproducible mortality rate of about $50 \%$ in mongrel dogs. We therefore thought to have an excellent model for our studies investigating the effects of primary resuscitation from traumatic hypotension by means of hypertonic saline colloid solution. At that time Konrad Messmer was Director of the Department of Experimental Surgery at the Ruprecht Karls University in Heidelberg and I was in his team. Michael Schoenberg and I started our first experimental series. The necessity to use dogs stemmed from the fact that we intended to measure regional organ blood flow by means of the radioactive microspheres method, i.e. a large animal model was needed. Since the animal rights movement led to regulations excluding animals not specifically bread for research purposes from investigations, we decided to use the beagle as experimental animal. The first experiments were disappointing, and nobody in the team understood why the uptake model didn't work although validated so nicely by Michael Schoenberg's research work in Sweden. It turned out that there was one fact that proved to be 'the' crucial factor: in contrast to former experiments, where mongrel dogs had been used, now we had beagles which we submitted to the identical shock procedure. After some experiments (and some time, also) we had to face the fact that the 'uptake model' didn't work properly in the beagle, since the outcome was far away from being reproducible. We decided to continue our research work in the beagle, but taking a fixed hypotension period, first $45 \mathrm{~min}$ of hemorrhagic hypotension (MAP $=40 \mathrm{~mm} \mathrm{Hg}$ ), then $75 \mathrm{~min}$ of traumatic-hemorrhagic hypotension - and the model worked properly, as documented in the literature [21, 47, 48]. However, our initial experiments appeared to be of specific impact for the development of standardized hemorrhagic shock models in dogs and the beagle in particular. Finally Konrad Messmer came to the simple conclusion: 'The beagle is no dog!'

\section{References}

1 Baker CC, Oppenheimer L, Stephens B, Lewis FR, Trunkey DD: Epidemiology of trauma deaths. Am J Surg 1980;140:144-150.

2 Smith JP, Bodai BI, Hill AS, Frey CF: Prehospital stabilization of critically injured patients: a failed concept. J Trauma 1985;25:65-70.

3 Penfield WG: The treatment of severe and progressive hemorrhage by intravenous injections. Am J Physiol 1919;48:121-132.
4 Silbert S: The treatment of thromboangiitis obliterans by intravenous injection of hypertonic salt solution: Preliminary report. JAMA 1926;86:1759-1761

5 De Felippe J Jr, Timoner J, Velasco IT, Lopes OU: Treatment of refractory hypovolaemic shock by $7.5 \%$ sodium chloride injections. Lancet 1980;ii:1002-1004.
6 Brooks DK, Williams WG, Manley RW, Whiteman P: Osmolar and electrolyte changes in hemorrhagic shock. Hypertonic solutions in the prevention of tissue damage. Lancet 1963; i:521-526.

7 Reinert M: Die Wirkung hypertonischer Kochsalzlösung im irreversiblen hämorrhagischen Schock der Ratte. Zeitschr Kreislaufforsch 1966;55:134-137. 
8 Baue AE, Tragus ET, Parkins WM: A comparison of isotonic and hypertonic solutions and blood flow and oxygen consumption in the initial treatment of hemorrhagic shock. J Trauma 1967;7:743-756.

9 Velasco IT, Pontieri V, Rocha e Silva M Jr, Lopes OU: Hyperosmotic $\mathrm{NaCl}$ and severe hemorrhagic shock. Am J Physiol 1980;239: 664-673.

10 Rocha e Silva M, Velasco IT, Nogueira da Silva RI, Oliveira MA, Negraes GA: Hyperosmotic sodium salts reverse severe hemorrhagic shock: other solutes do not. Am J Physiol 1987;253: H751-H762.

11 Meßmer K: Die Wirkung hypertoner Lösungen bei Ratten im irreversiblen Schock. Anaesthesist 1968;17:295-299.

12 McNamara JJ, Mills D, Aaby GV: Effect of hypertonic glucose on hemorrhagic shock in rabbits. Ann Thorac Surg 1970;9:116-121.

13 Cone JB, Wallace BH, Caldwell FT Jr, Smith SD, Searcey R: Beneficial effects of a hypertonic solution for resuscitation in the presence of acute hemorrhage. Am J Surg 1987;154 585-588.

14 Traverso LW, Bellamy RF, Hollenbach SJ, Witcher LD: Hypertonic sodium chloride solutions: Effect on hemodynamics and survival after hemorrhage in swine. J Trauma 1987;27 32-39.

15 Smith GJ, Kramer GC, Perron P, Nakayama S Gunther RA, Holcroft JW: A comparison of several hypertonic solutions for resuscitation of bled sheep. J Surg Res 1985;39:517-528.

16 Kramer GC, Perron PR, Lindsey DC, Ho HS, Gunther RA, Boyle WA, Holcroft JW: Smallvolume resuscitation with hypertonic saline dextran solution. Surgery 1986;100:239-247.

17 Maningas PA, de Guzman LR, Tillman FJ, Hinson CS, Priegnitz KJ Volk KA, Bellamy RF: Small-volume infusion of $7.5 \% \mathrm{NaCl}$ in $6 \%$ Dextran 70 for the treatment of severe hemorrhagic shock in swine. Ann Emerg Med 1986;15:1131-1137.

18 Walsh JC, Perron PR, Holcroft JW, Gunther RA, Kramer GC: Comparison of resuscitation of hypovolemia using hypertonic saline-dextran and hypertonic saline-hetastarch. Circ Shock 1988:24:248.

19 Vincent JL, Armistead CW, Preiser JC, Thuc IM, De Backer D: Hypertonic hydroxyethylstarch for fluid resuscitation in endotoxin shock. Circ Shock 1988;24:203.

20 Kreimeier U, Messmer K: New perspectives in resuscitation and prevention of multiple organ system failure; in Baethmann A, Messmer K (eds): Surgical Research: Recent Concepts and Results. Berlin, Springer, 1987, pp 39-50.

21 Kreimeier U, Brückner UB, Messmer K: Improvement of nutritional blood flow using hypertonic-hyperoncotic solutions for primary treatment of hemorrhagic hypotension. Eur Surg Res 1988;20:277-279.

22 Hernandez LA, Grisham MB, Twohig B, Arfors K-E, Harlan JM, Granger DN: Role of neutrophils in ischemia-reperfusion-induced microvascular injury. Am J Physiol 1987;253: H699-H703.
23 Granger DN, Benoit JN, Suzuki M, Grisham MB: Leukocyte adherence to venular endothelium during ischemia- reperfusion. Am J Physiol 1989;20:G683-G688.

24 Thiel M, Buessecker F, Eberhardt K, Chouker A, Setzer F, Kreimeier U, Arfors KE, Peter K, Messmer K: Effects of hypertonic saline on expression of human polymorphonuclear leukocyte adhesion molecules. J Leukoc Biol 2001;70:261-273.

25 Lehr HA, Saetzler RK, Thiel M, Arfors KE: Microvascular salvage by small volume resuscitation with hypertonic fluids: concepts and facts; in Messmer K (ed): Compromised Perfusion. Prog Appl Microcirc. Basel, Karger, 1996, vol 22, pp 167-180.

26 Nolte D, Bayer M, Lehr HA, Becker M, Krombach F, Kreimeier U, Messmer K: Attenuation of postischemic microvascular disturbances in striated muscle by hyperosmolar saline dextran. Am J Physiol 1992;263:H1411-H1416.

27 Steinbauer M, Harris A, Hoffmann T, Messmer K: Pharmacological effects of dextrans on the postischemic leukocyte-endothelial interaction; in Messmer K (ed): Compromised Perfusion. Prog Appl Microcirc. Basel, Karger, 1996, vol 22, pp 114-125.

28 Steinbauer M, Harris AG, Leiderer R, Abels C, Messmer K: Impact of dextran on microvascular disturbances and tissue injury following ischemia/reperfusion in striated muscle. Shock 1998;9:345-351.

29 Menger MD, Thierjung C, Hammersen F, Messmer K: Dextran vs. hydroxyethylstarch in inhibition of postischemic leukocyte adherence in striated muscle. Circ Shock 1993;41:248255.

30 Kreimeier U, Messmer K: Small-volume resuscitation; in Kox WJ, Gamble J (eds): Fluid Resuscitation. Baillière's Clinical Anaesthesiology, vol 2. London, Baillière Tindall, 1988, pp 545-577.

31 Mazzoni MC, Borgstroem P, Arfors KE, Intaglietta M: Dynamic fluid redistribution in hyperosmotic resuscitation of hypovolemic hemorrhage. Am J Physiol 1988;255:H629-H637.

32 Kreimeier U, Frey L, Pacheco A, Messmer K: Hypertonic volume therapy: A feasible regimen to contribute to the prevention of multiple organ failure? in Faist E, Ertel W (eds): Host Defense Dysfunction in Trauma, Shock and Sepsis. Mechanisms and Therapeutic Approaches. Berlin, Springer, 1993, pp 831-841.

33 Suzuki K, Ogino R, Nishina M, Kohama A: Effects of hypertonic saline and Dextran 70 on cardiac functions after burns. Am J Physiol 1995;268:H856-H864.

34 Welte M, Goresch T, Frey L, Holzer K, Zwissler B, Messmer K: Hypertonic saline dextran does not increase cardiac contractile function during small volume resuscitation from hemorrhagic shock in anesthetized pigs. Anesth Analg 1995;80:1099-1107.

35 Vassar MJ, Holcroft JW: Use of hypertonichyperoncotic fluids for resuscitation of trauma patients. J Intensive Care Med 1992;7:189_ 198.
36 Mazzoni MC, Borgström P, Intaglietta M, Arfors KE: Capillary narrowing in hemorrhagic shock is rectified by hyperosmotic saline-dextran reinfusion. Circ Shock 1990;31:407-418.

37 Mazzoni MC, Lundgren E, Arfors KE, Intaglietta M: Volume changes of an endothelial cell monolayer on exposure to anisotonic media. J Cell Physiol 1989;140:272-280.

38 Marti-Cabrera M, Ortiz JL, Durá JM, Cortijo J, Barrachina MD, Morcillo E: Hemodynamic effects of hyperosmotic mannitol infusion in anesthetized open-chest dogs: Modification by cyclooxygenase inhibition. Research in Surgery 1991;3:29-33.

39 Rabinovici R, Yue TL, Krausz MM, Sellers TS, Lynch KM, Feuerstein G: Hemodynamic, hematologic and eicosanoid mediated mechanisms in 7.5 percent sodium chloride treatment of uncontrolled hemorrhagic shock. Surg Gynecol Obstet 1992;175:341-354.

40 Kien ND, Kramer GC, White DA: Acute hypotension caused by rapid hypertonic saline infusion in anesthetized dogs. Anesth Analg 1991; 73:597-602.

41 Buga GM, Gold ME, Fukuto JM, Ignarro LJ: Shear stress-induced release of nitric oxide from endothelial cells grown on beads. Hypertension 1991;17:187-193.

42 Wade CE, Hannon JP, Bossone CA, Hunt MM, Loveday JA, Coppes RI, Gildengorin VL: Neuroendocrine responses to hypertonic saline/ dextran resuscitation following hemorrhage. Circ Shock 1991;35:37-43.

43 Younes RN, Aun F, Ching CT, Goldenberg DC, Franco MH, Miura FK, Santos SS, Sequeiros IMM, Rocha e Silva M, Fujimura I, Birolini D: Prognostic factors to predict outocome following the administration of hypertonic/hyperoncotic solution in hypovolemic patients. Shock 1997;7:79-83.

44 Mattox KL, Maningas PA, Moore EE, Mateer JR, Marx JA, Aprahamian C, Burch IM, Pepe PE: Prehospital hypertonic saline/dextran infusion for post-traumatic hypotension - the U.S.A. multicenter trial. Ann Surg 1991;213: 482-491.

45 Vassar MJ, Fischer RP, O’Brien PE, Bachulis BL, Chamber JA, Hoyt DB, Holcroft JW: A multicenter trial for resuscitation of injured patients with $7.5 \%$ sodium chloride: The effect of added dextran 70. Arch Surg 1993;128. 1003-1013.

46 Wade CE, Kramer GC, Grady JJ, Fabian TC, Younes RN: Efficacy of hypertonic 7.5\% saline and $6 \%$ dextran-70 in treating trauma: A metaanalysis of controlled clinical studies. Surgery 1997;122:609-616.

47 Kreimeier U, Brückner UB, Schmidt J, Messmer K: Instantaneous restoration of regional organ blood flow after severe hemorrhage: Effect of small-volume resuscitation with hypertonic-hyperoncotic solutions. J Surg Res 1990;49:493-503.

48 Kreimeier U, Brückner UB, Niemczyk S, Messmer K: Hyperosmotic saline dextran for resuscitation from traumatic-hemorrhagic hypotension: Effect on regional blood flow. Circ Shock 1990;32:83-99. 